\title{
Multi-Level, Bilateral Pedicle Fractures: Case Report
}

\author{
Çok Seviyeli, İki Tarafl Pedikül Kirtkları: Olgu Sunumu
}

Nuri KARABAY, Eren OZER, Emel ADA

Dokuz Eylul University, School of Medicine, Department of Radiology, Inciralti, Turkey

Corresponding Author: Nuri KARABAY / E-mail: nurikarabay@gmail.com

\begin{abstract}
Bilateral pedicle fracture is an extremely rare entity and few cases have been reported in literature. A case of bilateral multi-level pedicle fractures involving four lumbar vertebrae is being presented. Bilateral pedicle stress fracture at L1 - L4 was observed in a 61-year-old woman presented with low back pain. There was no any predisposing factor like trauma, spinal surgery, smoking or alcohol consumption except mild osteoporosis and bisphosphonate usage in the patient's medical history. We are unable to determine whether the fractures are related to osteoporosis or bisphosphonate therapy but these are the only remaining suspected reasons in the present case. Further studies are required to define the effect of bisphosphonates usage on vertebral segments.
\end{abstract}

KEYWORDS: Bilateral pedicle fractures, Multi-level, Osteoporosis, Bisphosphonates usage

öz

Bilateral pedikül kırığı oldukça nadir bir klinik tablodur. Bel ağrısı şikayeti ile başvuran 61 yaşındaki kadın hastada L1- L4 düzeyinde bilateral pedikül kırığı izlendi. Klinik öyküde osteoporoz ve bifosfonat kullanımı dışında herhangi bir predispozan faktör yoktu. Bifosfonat kullanımının vertebralar üzerine olan etkisinin tanımlanabilmesi için daha fazla sayıda çalışmaya ihtiyaç vardır.

ANAHTAR SÖZCÜKLER: İki taraflı pedikül kırığı, Çok-seviyeli, Osteoporoz, Bifosfonat kullanımı

\section{INTRODUCTION}

Bilateral multi-level pedicle fracture is an extremely rare condition and is generally associated with previous spine surgery or stress-related activities $(2,6,7)$. We report a case of bilateral multi-level (four levels) pedicle fracture that was not associated with any obvious risk factors except bisphosphonate usage for osteoporosis. No such case has been previously reported in the literature.

\section{CASE REPORT}

A 61-year-old woman was admitted to our outpatient clinic with low back pain twoyears ago. Lumbo-sacral vertebral direct radiographies and computed tomography (CT) (Figure 1A-E) scan, obtained two years ago, showed grade 1 compression fractures on the end plates that could be associated with osteoporosis but no fracture line was seen at the pedicles. Conservative therapy (analgesic medications and resting) was suggested by the physician for the patient's complaints. After two-years, the patient was re-admitted to our clinic because of the worsening of her low back pain. There was no trauma, spinal surgery, smoking or alcohol consumption in her medical history but there was usage of bisphosphonate $(70 \mathrm{mg}$ once a week) and vitamin D for postmenopausal osteoporosis (dualenergy $\mathrm{x}$-ray absorptiometry results indicated decreased bone density compatible with osteoporosis; the mean T-score of the lumbar spine was $-3,0$ at the start of treatment) for the last four years. Physical examination showed mild reduction in all back movements and tenderness on the spinous process at the lumbar region. Computed tomographic scans (Figure $2 \mathrm{~A}-\mathrm{E} ; 3 \mathrm{~A}, \mathrm{~B}$ ) revealed the presence of a bilateral pedicle stress fracture of the lumbar vertebrae with pseudoarthrosis (at L1L4 levels) and incomplete fracture at the upper side of the right $L 5$ vertebra pedicle. There were also grade 1 compression fractures on the end plates due to mild osteoporosis but we could not find any other bone abnormalities in the vertebrae (such as lytic lesion or anything else).

Surgical treatment (posterior spinal fusion) was suggested to the patient. However she declined surgical intervention and underwent a physical therapy program.

\section{DISCUSSION}

Stress fractures occur in normal or abnormal bone when repetitive mechanical load exceeds the biological capacity of the bone. Fatigue fracture is a type of stress fracture, and is due to abnormal stresses on normal bone, while insufficiency fractures occur when normal physiological stress is applied to bone with deficient elastic resistance or mineral content (14). Vertebral pedicles are a component of the neural arch like the pars interarticularis and are vulnerable to cyclic loads. However, pedicle stress fractures are much less common than pars interarticularis fractures in the spine. In a study of the matter, Cyron et al. reported five pedincular stress fractures compared to 55 pars interarticularis fractures subjected to cyclic shear loads (1). A study by Robertson et al. can clarify that condition; they stated that the pedicle has greater intrinsic strength and a shorter moment arm from the 


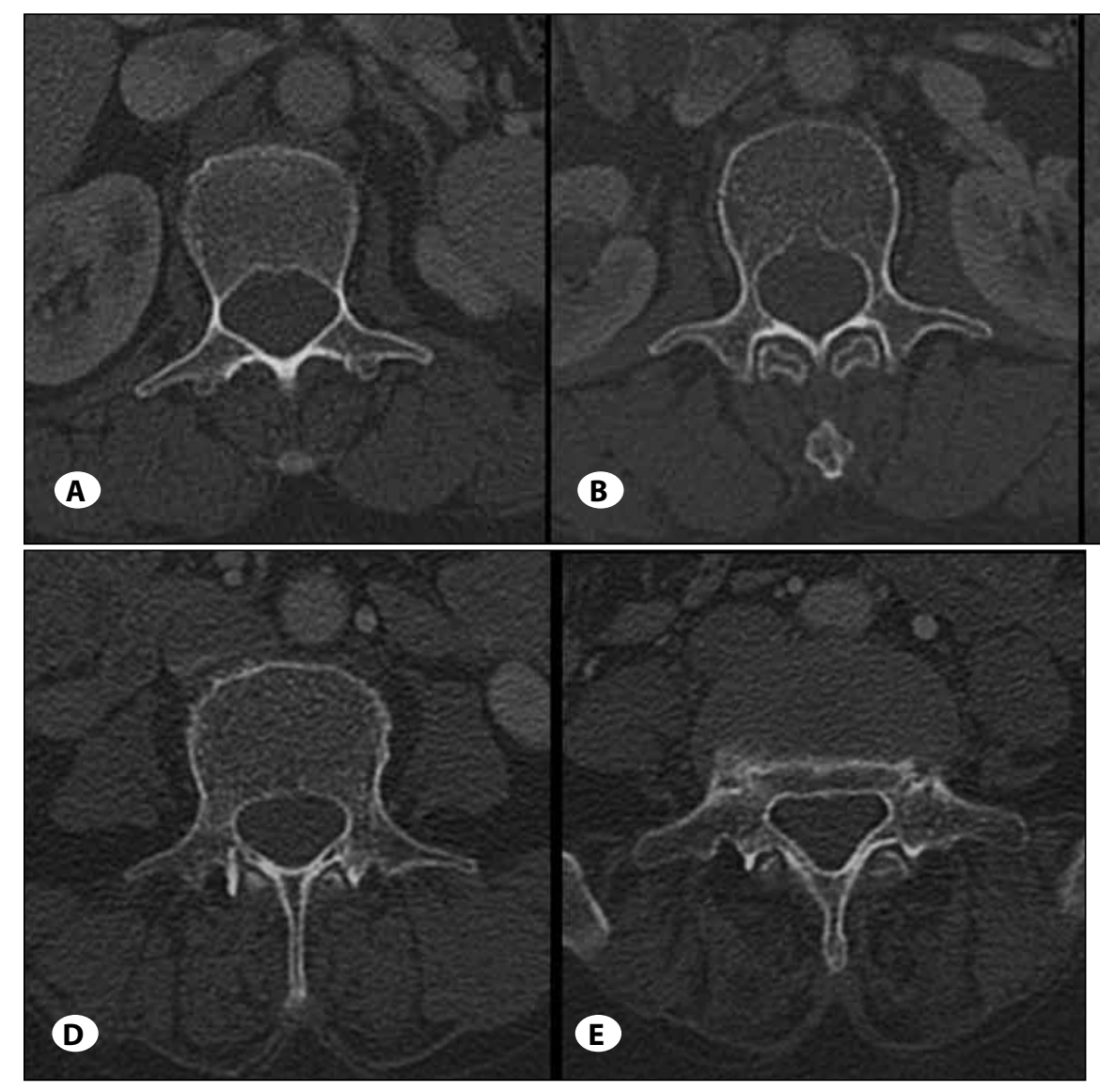

Figure 1: Computed tomographic scan of spine obtained 2 years ago showed no fracture lines at L1 to L5 (A-E) vertebral pedicles.
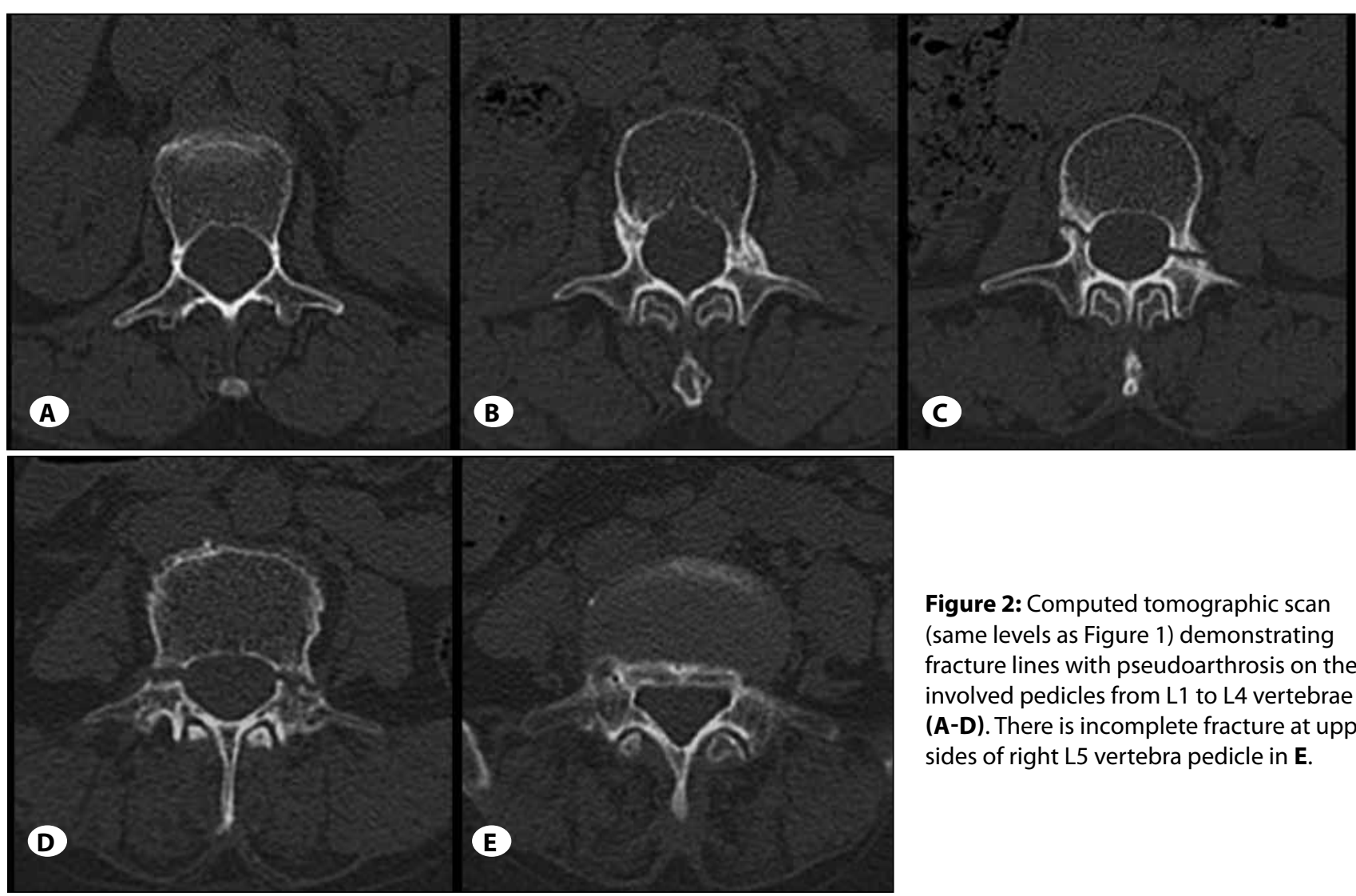

Figure 2: Computed tomographic scan (same levels as Figure 1) demonstrating fracture lines with pseudoarthrosis on the involved pedicles from L1 to L4 vertebrae (A-D). There is incomplete fracture at upper sides of right $L 5$ vertebra pedicle in $\mathbf{E}$. 

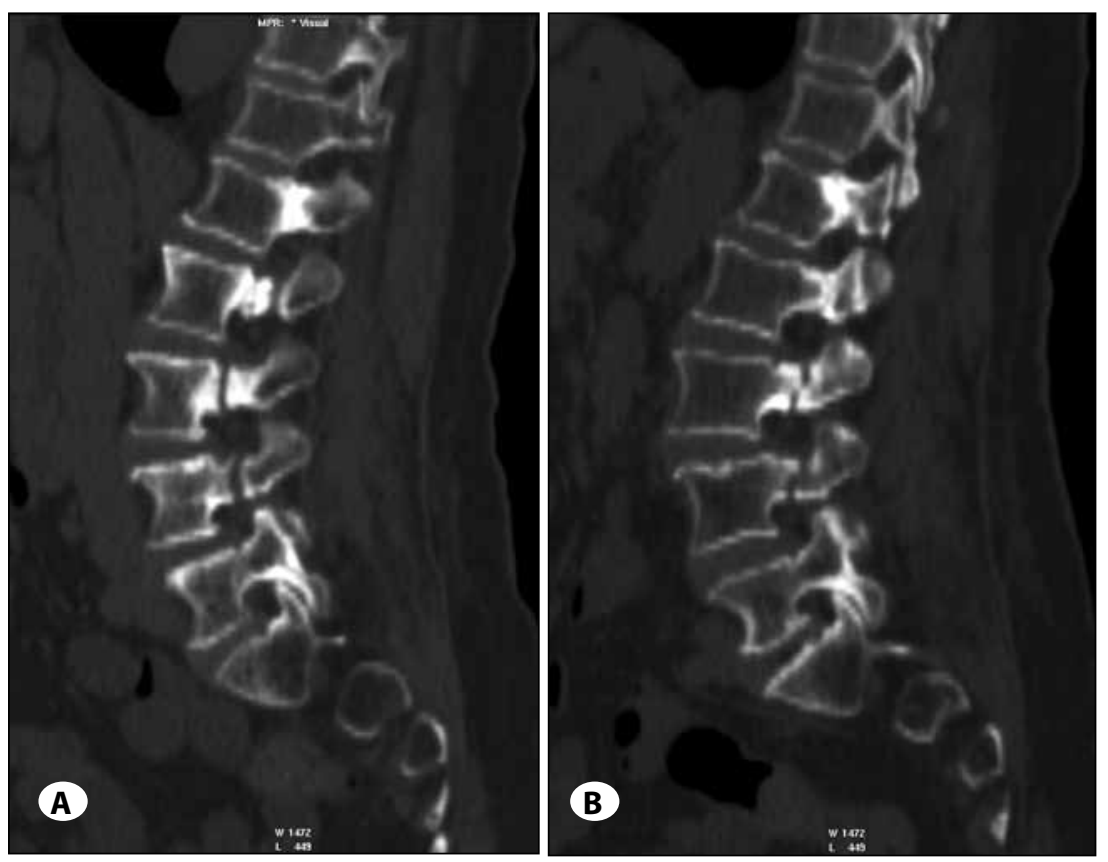

Figure 3: Parasagittal reformatted computed tomography images showing L1-L4 pedicle fractures on $\mathbf{A}$ ) right and $\mathbf{B}$ ) left sides.

vertebral body and therefore can resist greater cyclic shear forces (12). In our patient, the pedicle fractures had sclerotic edges compatible with pseudoarthosis, thus, we guess that continuous fatiguing stresses caused the fractures on the osteoporotic pedicles.

Bilateral pedicle stress fracture is a rare entity and we found that few cases have been reported in literature and underlying causative factors like previous spine surgery, spondylolysis or spondylolisthesis were described in these cases $(2,6-8,13)$. The pedicle may be exposed to increased forces after spine surgery, especially after spinal fusion, and the few pedicle stress fracture cases after surgery that occurred at the most proximal level of the fusion have been reported $(3,9,12)$. Similarly, only some cases of bilateral pedicle stress fracture have also been reported to be related with only patient's daily living activity $(5,11)$. Osteoporosis causes mineral and structural changes and leads to an increased risk of stress fractures due to the weaken structure of bones. Stress fracture of the pedicle was reported in an elderly female patient caused axial osteoporosis and producing a spondylolisthesis (15). Kim et al. also reported that a severe osteoporotic patient had bilateral pedicle stress fractures involving two adjacent vertebras together with spondylolisthesis (8). According to our knowledge, there is no previously reported case of multi-level (involving four consecutive vertebrae) bilateral pedicle stress fracture. Our patient did not have any predisposing risk factors for pedicle fractures except osteoporosis and bisphosphonate usage. We can find just one case who had bilateral pedicle fracture at one level associated with bisphosphonate therapy (the patient had been using risedronate for 10 years) in the literature (4). Odvina et al. found nine patients with spontaneous non-pathological fractures that developed during daily living activities (such as walking, standing, etc.) after long-term bisphosphonate use since 2005
(10). They concluded that long-term alendronate treatment causes strong suppression in bone turnover and lead atypical localized fractures, especially femur body fractures but nonspinal. Actually, we could not know whether the fractures were related to osteoporosis or bisphosphonate therapy but these remain as the possible causes in the present case.

\section{CONCLUSION}

We report a unique case of multi-level bilateral pedicle stress fractures in consecutive four vertebrae occurring in the absence of major trauma, previous spine surgery, or stressrelated activity except bisphosphonate use for osteoporosis. Furthermore, studies are required to define the effect of bisphosphonates usage on vertebral segments.

\section{REFERENCES}

1. Cyron BM, Hutton WC, Troup JD: Spondylolytic fractures. J Bone Joint Surg Br 58-B: 462-466, 1976

2. Doita $M$, Ando $Y$, Hirata $S$, Ishikawa $H$, and Kurosaka $M$ : Bilateral pedicle stress fracture in a patient with osteoporotic compression fracture. Eur Spine J 18 Suppl 2: 206-209, 2009

3. Doita M, Shimomura T, Nishida K, Maeno K, Fujioka H, Kurosaka M: Bilateral pedicle stress fracture in a patient with lumbar spinal stenosis: A case report. J Spinal Disord Tech 21: 531-534, 2008

4. El Rachkidi R, Sari-Leret ML, Wolff S: Atypical bilateral pedicle fracture in long-term bisphosphonate therapy. Spine (Phila Pa 1976) 36: E1769-1773, 2011

5. Gunzburg R, Fraser RD: Stress fracture of the lumbar pedicle. Case reports of "pediculolysis" and review of the literature. Spine (Phila Pa 1976) 16: 185-189, 1991

6. Ha KY, Kim YH: Bilateral pedicle stress fracture after instrumented posterolateral lumbar fusion: A case report. Spine (Phila Pa 1976) 28: E158-160, 2003 
7. Kim HS, Ju Cl, Kim SW: Bilateral pedicle stress fracture accompanying spondylolysis in a patient with ankylosing spondylitis. J Korean Neurosurg Soc 48: 70-72, 2010

8. Kim HS, Kim SW, Lee WT: Spondylolisthesis accompanying bilateral pedicle stress fracture at two vertebrae. J Korean Neurosurg Soc 51: 388-390, 2012

9. Macdessi SJ, Leong AK, Bentivoglio JE: Pedicle fracture after instrumented posterolateral lumbar fusion: A case report. Spine (Phila Pa 1976) 26: 580-582, 2001

10. Odvina CV, Zerwekh JE, Rao DS, Maalouf N, Gottschalk FA, Pak CY: Severely suppressed bone turnover: A potential complication of alendronate therapy. J Clin Endocrinol Metab 90: 1294-1301, 2005
11. Parvataneni HK, Nicholas SJ, McCance SE: Bilateral pedicle stress fractures in a female athlete: Case report and review of the literature. Spine (Phila Pa 1976) 29: E19-21, 2004

12. Robertson PA, Grobler LJ: Stress fracture of the pedicle. A late complication of posterolateral lumbar fusion. Spine (Phila Pa 1976) 18: 930-932, 1993

13. Sadiq MZ: Bilateral pedicle stress fracture in the lumbar spine of a sedentary office worker. Eur Spine J 15 Suppl 5: 653-655, 2006

14. Schaffler MB, Radin EL, Burr DB: Long-term fatigue behavior of compact bone at low strain magnitude and rate. Bone 11: 321-326, 1990

15. Tabrizi P, Bouchard JA: Osteoporotic spondylolisthesis: A case report. Spine (Phila Pa 1976) 26: 1482-1485, 2001 